\title{
Primary hyperparathyroidism due to ectopic mediastinal parathyroid gland at the level of anterior wall of ascending aorta.
}

Gogali F', Tzatzadakis N², Proikaki S', Samartzis G', Prokovas I', Tsentidis C1

\section{Department of Endocrinology \& Diabetes 2. Department of Thoracic Surgery Nikaea-Piraeus General Hospital "Agios Panteleimon"}

IN T R O D U C T IO N

Parathyroid adenoma is the most common cause of primary hyperparathyroidism (PHPT) resulting in hypercalcemia and hypercalciuria due to autonomous secretion of PTH. Ectopic parathyroid adenoma, as a consequence of variability in the glandular tissue migration during the embryologic life or a super numary fifth parathyroid gland, has an incidence of $25 \%$ among patients with PHPT. The incidence of deeply mediastinal ectopic parathyroid adenoma is 1-3\%.

\section{A S E R E P O R T}

We report the case of a 61-year-old woman who was discovered with hypercalcemia during routine check for postmenopausal osteoporosis. Calcium levels ranged between 10,8 and $12 \mathrm{mg} / \mathrm{dl}(8,5-10,2)$, with increased PTH levels $203 \mathrm{pg} / \mathrm{ml}(10-$ 65) $\mathrm{P}=2,5 \mathrm{mg} / \mathrm{dl}$ (2.4-4.9), Creat $=0.8 \mathrm{mg} / \mathrm{dl}(0.6-1.2)$, $25(\mathrm{OH}) \mathrm{D}_{3}=23,2 \mathrm{ng} / \mathrm{ml}(10-60), \mathrm{ALP}=204 \mathrm{U} / \mathrm{L}(<280)$ and $\mathrm{Mg}=2,1 \mathrm{mg} / \mathrm{dl}(1,6-2,4)$. The $24 \mathrm{hour}$ urinary Ca was elevated $343 \mathrm{mg} / 24 \mathrm{~h} \quad(100-300)$ and $P=507 \mathrm{mg} / 24 \mathrm{~h}$ (350-1300). DXA screening revealed osteoporosis in both lumbar spine and femoral neck. Primary hyperparathyroidism was diagnosed and further investigation for localization of the adenoma was carried out. Cervical sonography was unremarkable. Tc-99m-sestamibi scintigraphy was carried out and an accumulation area indicating ectopic parathyroid tissue in the anterior mediastinum, at the level of aortic arch, was demonstrated. Additionally chest-cervical CT scan revealed a $1,7 \mathrm{~cm}$ nodule in the anterior mediastinum at the level of anterior wall of ascending aorta. The patient underwent surgical resection of the ectopic parathyroid gland by median sternotomy. PTH and calcium serum levels normalized after surgery $(41 \mathrm{pg} / \mathrm{ml}$ and $9.5 \mathrm{mg} / \mathrm{dl}$ respectively). No calcium and/or alfacalcidol supplements were needed postoperatively.

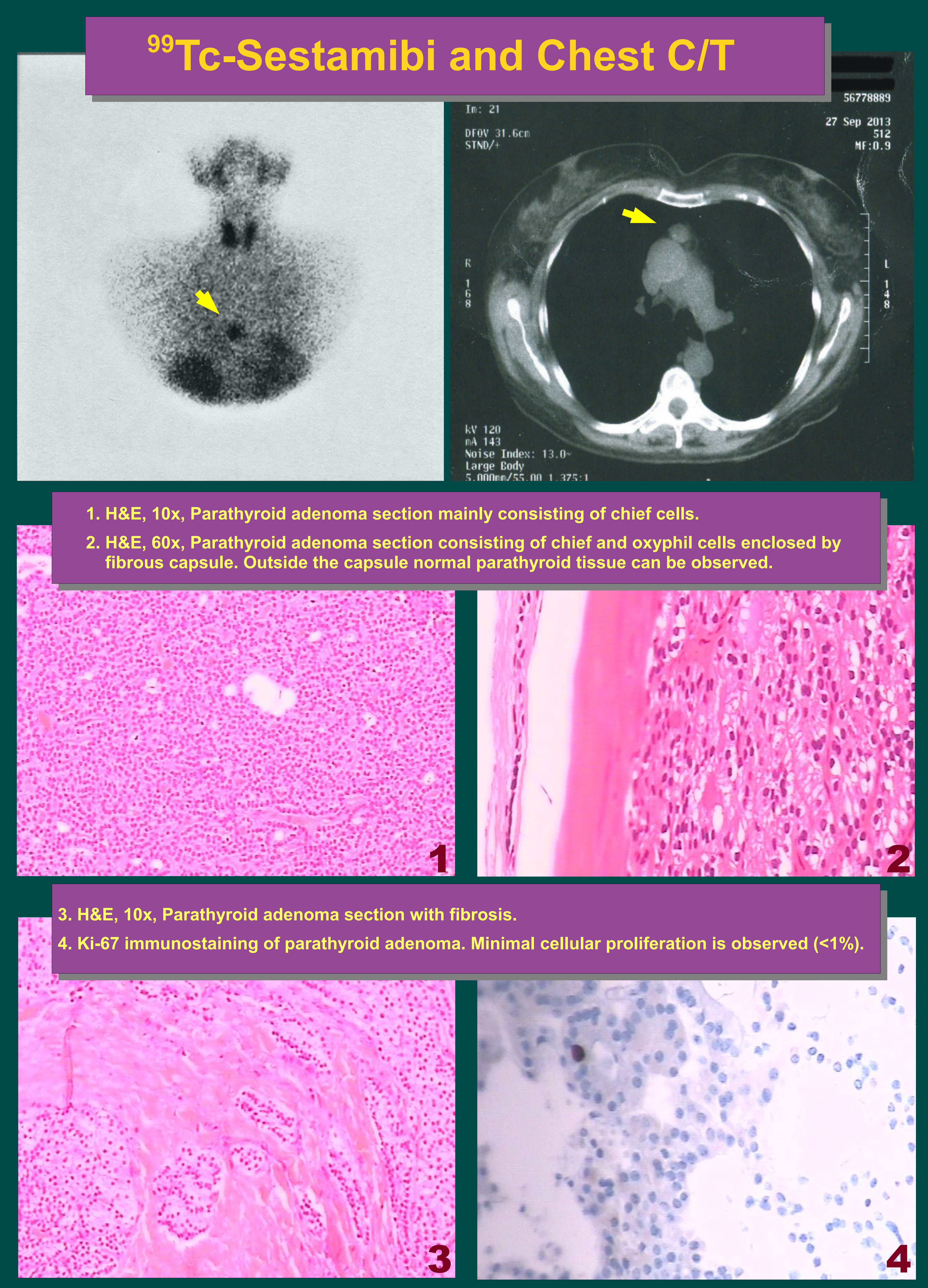

C O N C L USIO N

291
Ectopic parathyroid adenomas with mediastinum localization proximal to ascending aorta are rare causes of primary hyperparathyroidism. Those masses are considered to be derived from migrating inferior parathyroid glands to anterosuperior mediastinum. Combination of Tc-99m sestamibi scintigraphy and chest-cervical CT scan are indispensable for the preoperative localization of oversecreting parathyroid tumors. 